\title{
MODOS E DOSES DE APLICAÇÃO DE INOCULANTE NA CULTURA DA SOJA
}

\author{
Cassiano Spaziani Pereira ${ }^{1 *}$, Lucas Balbinot ${ }^{1}$, Ivan Vilela Andrade Fiorini ${ }^{1}$, Renan Rimoldi Tavanti ${ }^{2}$ Letícia Carolina Costa $^{2}$ \\ 1 Universidade Federal do Mato Grosso,78556-186, Sinop, Brasil. \\ ${ }^{2}$ Universidade Estadual Paulista - Unesp “Júlio de Mesquita Filho”, 15385-000 \\ *E-mail: caspaziani@yahoo.com.br
}

Recebido em:15/06/2018

Aceito em:26/04/2019

\begin{abstract}
RESUMO
A inoculação é considerada uma das práticas mais importante na cultura da soja. O objetivo do trabalho foi verificar o efeito de diferentes doses de inoculante com Bradyrhizobium japonicum sob diferentes modos de aplicação. O delineamento experimental utilizado foi em blocos casualizados completos (DBC) com 4 repetições em esquema experimental fatorial 4 x 3, totalizando 12 tratamentos. As doses foram: 0; 400; $800 \mathrm{e} 1200 \mathrm{~mL}$ de inoculante $50 \mathrm{~kg}^{-1}$ de sementes ou mL ha-1 quando o inoculante foi aplicado na cobertura. Os três modos de aplicação foram: via semente (semeadura), via pulverização foliar no estádio em V2 e diretamente no solo com a adição de $50 \mathrm{~g}$ de gelatina bovina em 4,0 $\mathrm{L}_{\text {água }}{ }^{-1}$ no estádio V2. A cultivar semeada foi a LG 60174 IPRO. Os tratamentos feitos com a gelatina bovina e ágar foram os que obtiveram os melhores resultados em altura de plantas, diâmetro de caule, número de folhas, área foliar, teor de clorofila, e massa seca da parte aérea, apresentando as maiores médias no crescimento vegetativo das plantas. A aplicação via semente atingiu as maiores médias de número de nódulos e na massa seca de nódulos, devido principalmente à proximidade da bactéria com a semente. Acredita-se que as gelatinas possam ter mantido a umidade do solo mais alta.
\end{abstract}

Palavras-chave: Glycine max. Inoculante. Bradyrhizobium japonicum.

\section{Introdução}

A soja (Glycine max (L.) Merrill), é um dos principais grãos consumidos no mundo. Considerado o "grão de ouro" pela sua cor e utilidade. Sua importância consiste no fato de ser base da alimentação de várias nações, o que faz dela uma relevante matéria-prima para a indústria, na alimentação humana e formulação de rações. O Brasil é o maior exportador e o segundo maior produtor mundial de soja, perdendo apenas para os Estados Unidos. Se somarmos a produção dos dois maiores produtores, esse atinge 324,1 milhões de toneladas, $92 \%$ da produção mundial de 351,8 milhões [18]. Dessa forma compreende-se a grandeza de tal cultura para o Brasil.

O principal elemento para da produção da soja é o nitrogênio, que está relacionado com o metabolismo vegetal, fotossíntese, respiração, crescimento, produção de flores, folhas e grãos [17]. O teor médio de proteína nos grãos de soja é de 6,5\%, o que exige grande quantidade de Nitrogênio $(\mathrm{N})$ para o seu desenvolvimento. Entretanto, o nitrogênio disponível naturalmente no ar, na matéria orgânica e no solo, não é suficiente para que os produtores possam atingir bons níveis de produtividade. Estima-se que a soja, necessite de $240 \mathrm{~kg} \mathrm{ha}^{-1}$ de N para atingir uma produtividade de aproximadamente $3.000 \mathrm{~kg} \mathrm{ha}^{-1}$ [5].
$\mathrm{O}$ suprimento de $\mathrm{N}$ pode acontecer de duas maneiras, a aplicação de adubo com fonte de $\mathrm{N}$ e a inoculação de bactérias fixadoras de N. A inoculação é a prática mais utilizada, utilizandose bactérias do gênero Bradyrhizobium, que infectam as raízes através dos pelos radiculares, formando nódulos $\mathrm{e}$ disponibilizando nitrogênio para a planta de forma simbiótica [2].

Trabalhos de pesquisa sobre inoculação realizados em vários locais do Brasil têm comprovado a maior eficiência produtiva da inoculação sobre a adubação nitrogenada na cultura da soja. Além disso, com a inoculação pode-se influenciar positivamente a qualidade dos solos ao evitar os problemas causados pelo uso de adubos nitrogenados [1]. A forma mais recomendada e eficiente de inoculação é a por meio das sementes [6], porém aplicações via foliar em cobertura são muito mais simples operacionalmente.

A inoculação é uma prática barata para o produtor, com valores em torno de 0,5 centavo de dólar a dose por hectare, porém ainda existem muitas perguntas a serem respondidas sobre determinada prática, principalmente quando a mesma é realizada em Mato Grosso, onde praticamente inexistem informações sobre essa prática de cultivo [12].

Mediante ao exposto, o objetivo do trabalho foi verificar o efeito de diferentes doses: 0; 400; 800; $1200 \mathrm{~mL}$ de inoculante Bradyrhizobium japonicum e três modos de aplicação: via 
semente, foliar e diretamente no solo, com a mistura de gelatina bovina e de ágar sobre o crescimento vegetativo, índice de clorofila e a nodulação de plantas de soja LG 60174 IPRO.

\section{Metodologia}

\subsection{Local e características do solo}

O experimento foi conduzido na casa de vegetação, pertencente ao setor do viveiro, da Universidade Federal do Mato Grosso, Campus de Sinop, localizado no município de Sinop, Mato Grosso. A casa de vegetação situa-se na latitude $11^{\circ} 98^{\prime} 22^{\prime \prime}$ $\mathrm{S}$ e longitude $55^{\circ} 56^{\prime} 59^{\prime \prime} \mathrm{W}$, sendo climatizada com temperatura controlada em $25.8^{\circ} \mathrm{C}$ e umidade relativa de $60 \%$. O período do trabalho foi de 23 de novembro de 2017 a 31 de janeiro de 2018.

O solo utilizado foi considerado argiloso e suas características químicas e físicas estão apresentadas nas Tabelas 1,2 e 3 .

Tabela 1 - Teores de $\mathrm{pH}$, macro nutrientes, alumínio, acidez potencial matéria orgânica e saturação de bases da análise de solo do experimento.

\begin{tabular}{|c|c|c|c|c|c|c|c|}
\hline pH & $\mathbf{K}$ & $\mathbf{C a}$ & Mg & Al & H & H+ & MO \\
\hline \multicolumn{2}{|c|}{----mg/dm³. } & \multicolumn{5}{|c|}{ 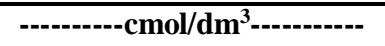 } & $---g / d^{3}-$ \\
\hline 5,4 & 1,11 & 1,16 & 0,66 & 0,1 & 4,1 & 4,2 & 28,2 \\
\hline
\end{tabular}

Tabela 2 - Areia, silte e argila, micronutrientes e enxofre da análise de solo do experimento.

\begin{tabular}{|c|c|c|c|c|c|c|c|c|}
\hline Areia & Silte & Argila & Zn & $\mathbf{C u}$ & $\mathbf{F e}$ & Mn & B & $\mathbf{S}$ \\
\hline \multicolumn{3}{|c|}{-----g/dm³ } & & & & & $\mathrm{a}$ & \\
\hline 379 & 162 & 459 & & 0,1 & 30 & 1,0 & 0,10 & 4,0 \\
\hline
\end{tabular}

Tabela 3 - Características do solo: $\mathrm{pH}$ em $\mathrm{CaCl}_{2}$; CTC a pH 7,0.

\begin{tabular}{cc}
\hline $\mathbf{p H}\left(\mathbf{C a C l}_{2}\right)$ & $\mathbf{C T C} \mathbf{a ~ p H ~ 7 , 0}$ \\
\hline 5,4 & $\mathbf{c m o l} / \mathbf{d m}^{\mathbf{3}}$ \\
\hline & 6,08 \\
\hline
\end{tabular}

\subsection{Delineamento e condução do experimento}

$\mathrm{O}$ delineamento experimental utilizado foi em blocos casualizados com quatro repetições, em esquema fatorial 4x3, totalizando 12 tratamentos. O primeiro fator deu-se pela aplicação de quatro doses de Bradyrhizobium japonicum: 0; 400; 800 e 1200 $\mathrm{mL} 50 \mathrm{~kg}^{-1}$ de sementes ou ha ${ }^{-1}$ de acordo com o modo de aplicação. A população de bactérias do inoculante utilizado foi de $5 \times 10^{9}$ UFC $\mathrm{mL}^{-1}$, estirpes SEMIA 5079 e SEMIA 5080. O segundo fator foram três diferentes modos de aplicação das doses de inoculante: via semente, via pulverização foliar no estádio V2 e diretamente no solo na forma líquida numa mistura de água e gelatina bovina na dose de $50 \mathrm{~g}$ de gelatina em 4,0 L água ${ }^{-1}$ no estádio V2. A aplicação nas sementes teve a dose atrelada a mL 50 $\mathrm{kg}^{-1}$ de sementes que é a quantidade de sementes considerada para que os tratamentos via foliar, gelatina bovina e ágar gastam para semear 1 hectare.

Os vasos possuíam 10L e antes de se iniciar o experimento foi determinada a capacidade de campo (CC) do solo pelo método de "conteúdo de água no solo" após saturação, através da ação da gravidade, até o cessamento da drenagem [15]. Coletouse $10 \mathrm{~kg}$ do solo a ser utilizado no experimento e realizou-se a secagem do mesmo ao sol. Posteriormente o solo foi saturado de água e deixado sem interferências até cessar a drenagem, após esse tempo, a massa do solo foi obtida. A restituição da água foi feita de acordo com a reposição necessária por tratamento, com turno de rega a cada três dias.

A correção do solo foi feita com calcário dolomítico na dose de 2 toneladas ha ${ }^{-1}$ de calcário, 20 dias antes da semeadura, irrigando-se os vasos diariamente, antes do início do experimento, para haver a reação do calcário. A adubação de base foi: $100 \mathrm{~kg}$ $\mathrm{ha}^{-1}$ de $\mathrm{KCl}$ e $100 \mathrm{~kg} \mathrm{ha}^{-1}$ de $\mathrm{P}_{2} \mathrm{O}_{5}$ por vaso, um dia antes da semeadura. Logo após a semeadura fez-se a aplicação de uma solução de micronutrientes, que possuía $120 \mathrm{~g} \mathrm{ha}^{-1}$ de manganês, $80 \mathrm{~g} \mathrm{ha}^{-1}$ de zinco. Durante o estágio fisiológico V3, para aumentar a nodulação e produtividade da soja, aplicou-se via foliar produtos a base de cobalto e molibdênio, na proporção de $5 \mathrm{~g}$ de Co e $42 \mathrm{~g}$ de Mo, sem aplicação na semente, como recomendado [8]. A semeadura do experimento ocorreu no dia 13 de dezembro de 2017, semeando-se 6 sementes por vaso a $2 \mathrm{~cm}$ de profundidade. A cultiva utilizada foi a LG 60174 IPRO, considerada precoce e sem nenhum tratamento de semente após a germinação e emergência foram selecionadas 2 plantas por vaso.

Durante o experimento não houve incidência de insetos e doenças, não sendo necessária a aplicação de inseticidas ou fungicidas na cultura. $\mathrm{O}$ controle de plantas daninhas foi feito através da monda.

\subsection{Variáveis analisadas e análise estatística}

Todas as variáveis foram obtidas no início do florescimento (R1) aos 40 dias após a semeadura (DAS). Avaliouse as 2 plantas dos 2 vasos, totalizando assim 4 plantas para cada parcela. Após as avaliações foram obtidas as médias de cada parcela.

Inicialmente determinou-se o índice de clorofila (cor verde das folhas) das plantas, com o auxílio do aparelho ClorofiLOG®, modelo CFL 1030, Falker®. Foram tomados quatro pontos de amostra no primeiro trifólio totalmente expandido de cada planta das parcelas. Os resultados foram expressos em Índice de Clorofila Falker® (ICF) que é adimensional.

A altura das plantas foi obtida com auxílio de uma trena graduada, medindo-se do solo até o meristema apical das plantas. Foram tomadas as alturas das quatro plantas da parcela e depois das medições obteve-se a altura média por parcela, com os resultados expressos em $\mathrm{cm}$. O diâmetro de caule foi obtido $5 \mathrm{~cm}$ de altura do solo com auxílio de um paquímetro digital, tomando- 
se os valores das quatro plantas da parcela e os resultados foram expressos em mm planta $^{-1}$.

Após a determinação das variáveis a campo, as plantas foram cortadas rente ao solo, acondicionadas em sacolas de papel e levadas para o laboratório do Viveiro Florestal da UFMT campus Sinop. No laboratório as folhas das plantas foram destacadas e contadas, obtendo-se o número de folhas plantas ${ }^{-1}$. Logo após obteve-se a área foliar em $\mathrm{cm}^{2}$, com o auxílio de um integrador de área foliar LICOR modelo LI -3010. Por fim as amostras foliares foram recondicionadas em sacos de papel e colocadas em uma estufa de circulação de ar forçado a $60^{\circ} \mathrm{C}$, até atingirem o peso constante, para obtenção da massa seca da parte aérea [13].

Posteriormente as avaliações de parte aérea, o solo com as raízes das plantas foi retirado dos vasos e através de um processo de lavagem em água corrente, separou-se o solo das raízes e logo após desassociou-se as raízes dos nódulos. Os nódulos foram então contados obtendo-se o número de nódulos totais. As raízes e nódulos foram armazenados separadamente em sacolinhas de papel e colocadas em estufa de circulação de ar forçado por 72 horas a $65^{\circ} \mathrm{C}$, obtendo-se a massa seca das raízes e a massa seca de nódulo.

Após todas as análises, os dados obtidos foram submetidos à análise de variância ao nível de 5\% de probabilidade com o auxílio do software SISVAR ${ }^{\circledR}$ [4]. As variáveis foram quantitativas e os modelos foram escolhidos baseado na significância dos coeficientes de regressão utilizando o teste " $t$ " adotando-se o nível de $5 \%$ de probabilidade de determinação, o valor do $\mathrm{r}^{\mathbf{2}}$ (SQRegressão/SQtratamentos) e no fenômeno biológico.

\section{Resultados e discussões}

Ao se realizar a análise de variância, verificou-se que houve significância da interação entre doses de inoculante e modos de aplicação para as variáveis: altura, diâmetro de caule, número de folhas, área foliar e o índice de clorofila Falker®. O número de nódulos e massa seca de nódulos foram influenciados isoladamente pelas doses de inoculante, e pelos modos de aplicação. A massa seca da parte área foi influenciada apenas pelo modo de aplicação do inoculante.

A aplicação de Bradyrhizobium via foliar não alterou a altura das plantas. A inoculação via semente reduziu o crescimento da altura das plantas de $1,41 \mathrm{~m}$ na testemunha para $0,99 \mathrm{~m}$ na dose de $1200 \mathrm{~mL} 50 \mathrm{~kg}^{-1}$ de sementes, redução de $29,78 \%$. O contrário ocorreu com a aplicação do inoculante via gelatina bovina e ágar, havendo aumento na altura das plantas. $\mathrm{O}$ maior valor ocorreu na dose $1200 \mathrm{~mL} \mathrm{ha}^{-1}$, atingindo $1,46 \mathrm{~m}$ enquanto na testemunha a altura foi de $1,04 \mathrm{~m}$. Na aplicação com ágar os valores foram $0,88 \mathrm{~m}$ na testemunha e o maior valor obtido foi de 1,20 m na dose de $800 \mathrm{~mL} \mathrm{ha}^{-1}$ (Figura 1).

As variáveis, diâmetro de caule, número de folhas e área foliar tiveram curvas de comportamento nos modos de aplicação semelhantes entre (Figuras 2, 3 e 4). A aplicação de inoculante via semente não alterou o diâmetro de caule. A aplicação via foliar aumentou o diâmetro de $3,64 \mathrm{~mm}$ na testemunha para $3,93 \mathrm{~mm}$ na dose de $1200 \mathrm{~mL} \mathrm{ha}^{-1}$, a aplicação via gelatina bovina foi o que mais se destacou no aumento do diâmetro do caule, atingindo 4,92 $\mathrm{mm}$ na dose $1200 \mathrm{~mL} \mathrm{ha}^{-1}$ (Figura 2).

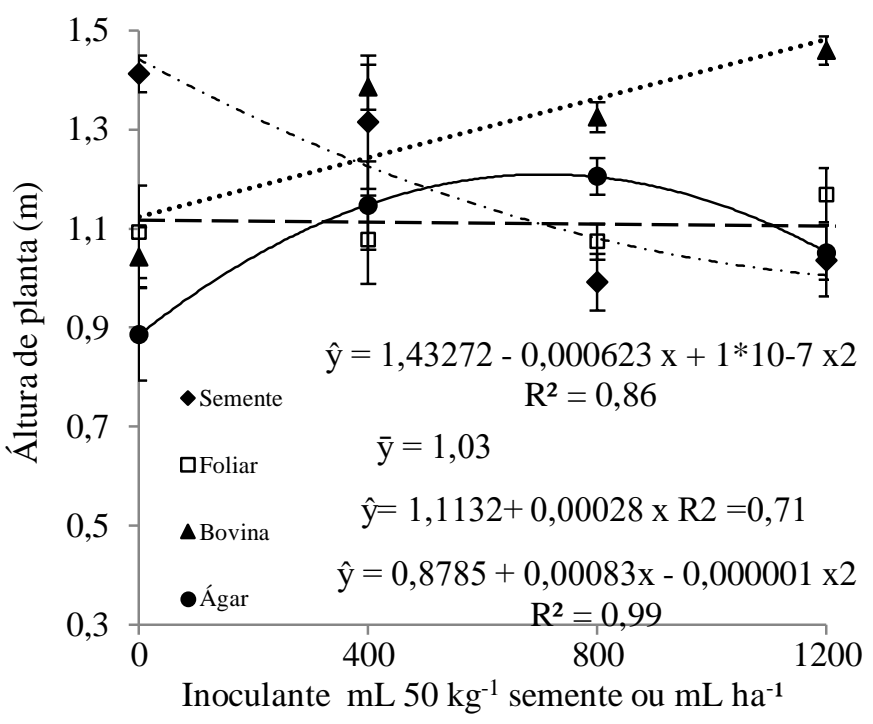

Figura 1: Altura de plantas de soja sob a aplicação de doses de inoculante Bradyrhizobium japonicum aplicado via sementes, foliar, gelatina bovina e gelatina a base de ágar.

Para o número de folhas, o maior incremento ocorreu nas aplicações via gelatina, ágar ou bovina. Para bovina, que foi a mais eficiente o aumento foi de 14,43 na testemunha para 21,56 folhas na dose de $1200 \mathrm{~mL} \mathrm{ha}^{-1}$. A aplicação via sementes teve 14,8 folhas na testemunha e atingiu 16,18 folhas na dose de $1200 \mathrm{~mL} 50 \mathrm{~kg}^{-1}$ sementes e via foliar 15,87 na testemunha e 17,31 na dose de 1200 $\mathrm{mL} \mathrm{ha}^{-1}$ (Figura 3).

Com relação a área foliar verificou-se que a aplicação de inoculante via semente não alterou esta variável. Assim como nas variáveis anteriores a aplicação de gelatina foram os tratamentos que mais se destacaram. A aplicação com gelatina bovina na dose $1200 \mathrm{~mL} \mathrm{ha}^{-1}$, atingiu o maior valor, $0,70 \mathrm{~m}^{2}$, aumento de $81 \% \mathrm{em}$ relação à testemunha. Para o ágar ocorreu atingiu a maior área, $0,49 \mathrm{~m}^{2}$ na dose de $800 \mathrm{~mL} \mathrm{ha}^{-1}, 42 \%$ inferior ao maior valor de área foliar encontrado com a aplicação de gelatina bovina. A aplicação foliar na maior dose atingiu $0,46 \mathrm{~m}^{2}$, aumento de $24 \%$ em relação a testemunha que teve área de $0,37 \mathrm{~m}^{2}$ (Figura 4).

Neste trabalho verificou-se um aumento do crescimento das plantas com o aumento nas doses de inoculantes $\mathrm{e}$ consequentemente nas concentrações de bactérias Bradyrhizobium 


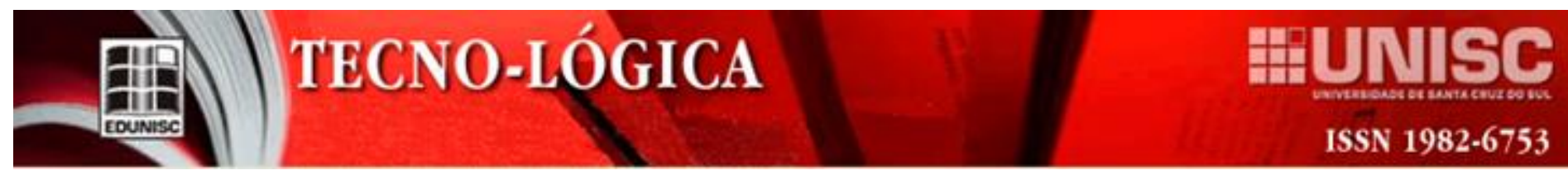

em contato com as plantas, o que aumenta a disponibilidade de nitrogênio para a soja e seu crescimento vegetativo. Fato também verificado com a avaliação de índice de clorofila ClorofiloG ${ }^{\circledR}$ (Figura 5). Segundo [14], o nitrogênio é um nutriente essencial para desenvolvimento das plantas e na ausência de suplementações deste nutriente, variáveis como a altura, o diâmetro do caule e a área foliar das plantas são afetadas negativamente.

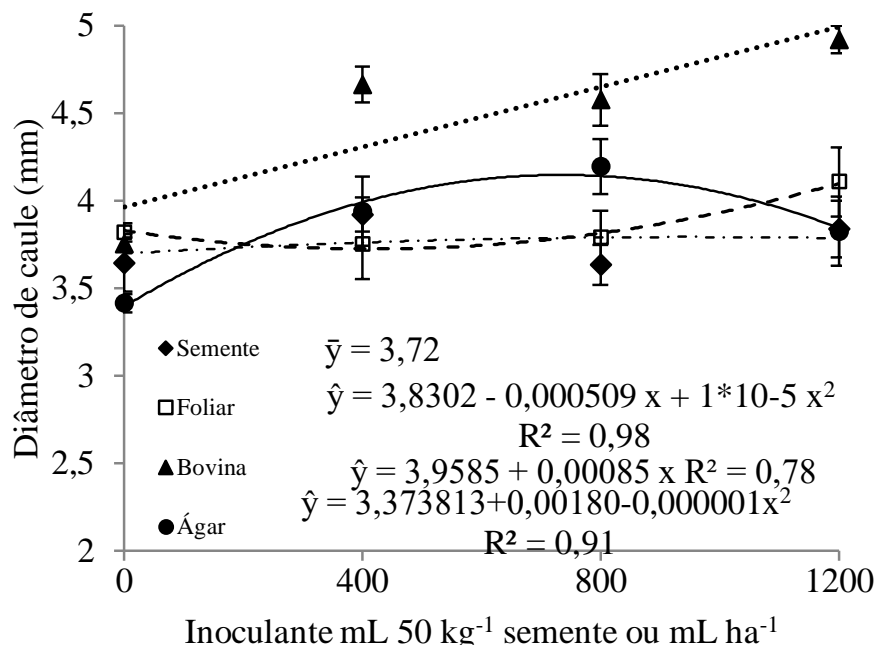

Figura 2. Diâmetro de caule de plantas de soja sob a aplicação de Doses (D) de inoculante Bradyrhizobium japonicum aplicado via sementes, foliar, gelatina bovina e gelatina a base de ágar

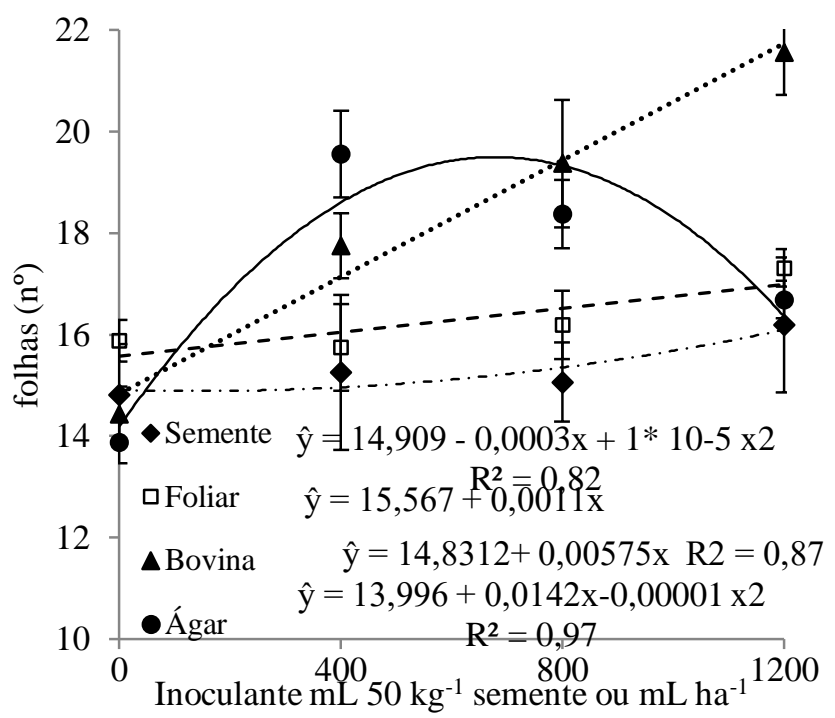

Figura 3. Número de folhas de plantas de soja sob a aplicação de Doses (D) de inoculante Bradyrhizobium japonicum aplicado via sementes, foliar, gelatina bovina e gelatina a base de ágar.

Em relação aos ganhos de crescimento vegetativo e índice de clorofila com a aplicação das gelatinas, pode-se associar as gelatinas o efeito destas ao dos polímeros hidroretentores, que aplicados no solo, melhoram a disponibilidade de água pelas plantas. As raízes ao crescerem por dentro dos grânulos do polímero hidratado alcançam um maior desenvolvimento de pêlos radiculares, gerando uma maior superfície de contato das raízes com a água e nutrientes, aumentando a absorção destes [10].

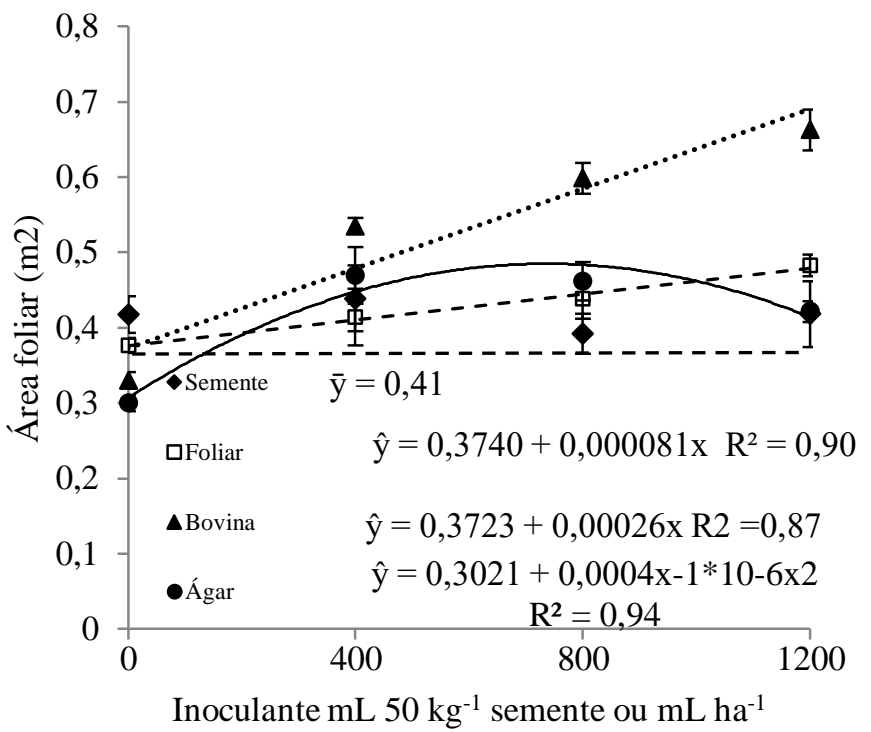

Figura 4. Área foliar de plantas de soja sob a aplicação de Doses de inoculante Bradyrhizobium japonicum aplicado via sementes (em mL $50 \mathrm{~kg}^{-1}$ de sementes), via foliar, gelatina bovina e ágar $\left(\mathrm{mL} \mathrm{ha}^{-1}\right)$.

Todos os tratamentos tiveram acréscimo nos valores de clorofiloG ${ }^{\circledR}$ com aumento nas doses de inoculante. Outros autores não verificaram alterações nos valores do índice de clorofila com a aplicação inoculação [12]. Porém [9], verificaram, assim como nesse trabalho aumento nos valores das leituras do teor de clorofila associando-os a aumentos nos teores de $\mathrm{N}$ foliar.

$\mathrm{O}$ índice clorofiloG® nos tratamentos com gelatina bovina e via pulverização foliar foram os que mais se destacaram. $\mathrm{Na}$ aplicação via sementes verificou-se na testemunha 28,79 , aumentando para 34,7 unidades de clorofiLOG® na dose $1200 \mathrm{~mL}$ $50 \mathrm{~kg}^{-1}$. A aplicação com gelatina bovina atingiu valores de 32,69 na testemunha para 35,80 unidades de clorofiLOG ${ }^{\circledR}$ na dose 1200 $\mathrm{mL} \mathrm{ha}^{-1}$. Via foliar houve aumento de 33,37 da testemunha para 35,66 unidades de clorofiLOG® na dose de $800 \mathrm{~mL} 50 \mathrm{~kg}^{-1}$ de sementes. Com a adição de ágar, os valores variaram de 30,68 para 33,64 unidades de clorofiLOG ${ }^{\circledR}$ na dose de $1200 \mathrm{~mL} \mathrm{ha}^{-1}$ (Figura $5)$.

O aumento nos valores de índice de clorofila verificados com a aplicação de inoculante em associação com as gelatinas bovina e ágar, podem ser explicados pelo melhor ambiente radicular/retenção de água propiciado por estes tratamentos, que consequentemente aumentaram crescimento vegetativo da soja também verificado nestes tratamentos anteriormente (Figuras 1; 2 


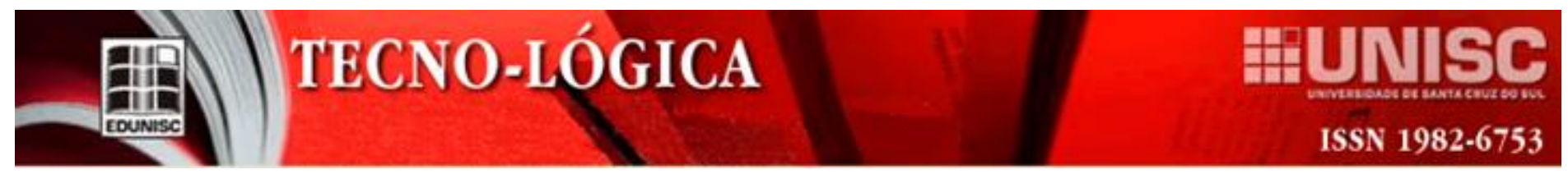

e 3). Segundo [17] quanto mais clorofila, maior será a produção de carboidratos (glicose e amido), consequentemente maior o crescimento vegetativo da planta.

Além disso, deve-se considerar o fato de a aplicação de inoculantes nos tratamentos com gelatina e foliar ter ocorrido em V3, num período mais próximo ao da avaliação desta variável do que a aplicação nas sementes que foi ainda na semeadura.

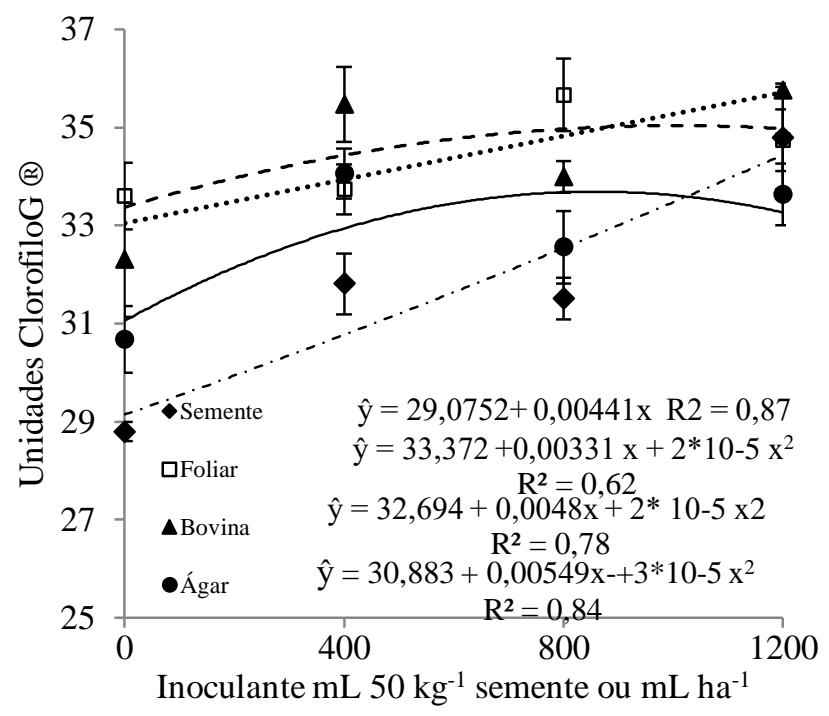

Figura 5: Teor de clorofila de plantas de soja sob a aplicação de doses de Bradyrhizobium japonicum aplicado via sementes, foliar, gelatina bovina e gelatina e ágar.

A massa seca das raízes não foi influenciada pelos tratamentos e teve média de $26,02 \mathrm{~g}$ de raízes planta ${ }^{-1}$. A massa seca e o número de nódulos foram influenciados apenas pelas doses de inoculante e os modos de aplicação, não havendo significância estatística da interação doses x modos de aplicação. A massa seca de nódulos variou de $0,96 \mathrm{~g}$ na testemunha até $3,45 \mathrm{~g}$ nos de $800{\mathrm{~mL} 50 \mathrm{~kg}^{-1} \text { de semente ou ha- }}^{-1}$ (Figura 6). O número de nódulos variou de 54,44 na testemunha até 103,56 unidades na maior dose (Figura 7). Estes aumentos ocorreram devido as maiores concentrações de células de Bradyrhizobium japonicum com os aumentos das doses do inoculante.

Entre os modos de aplicação do inoculante verifica-se que a aplicação via sementes foi o que mais se destacou na formação de nódulos atingindo até 116,69 unidades, superior as outras três formas de aplicação, que não se diferenciaram entre si (Tabela 4). O comportamento da massa seca foi semelhante ao do número de nódulos, porém em tal variável a aplicação via sementes e foliar foram semelhantes entre as mesmas se destacando da aplicação via gelatina (Tabela 4).

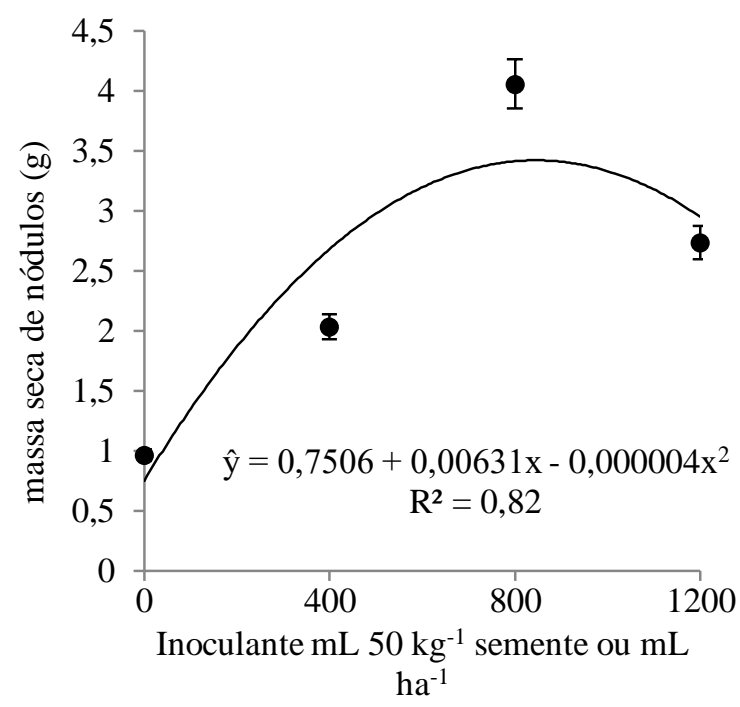

Figura 6: Massa Seca de Nódulos de plantas de soja sob a aplicação de doses de inoculante Bradyrhizobium japonicum aplicado via sementes, foliar, gelatina bovina e gelatina a base de ágar.

Para a massa seca da parte aérea, as maiores médias foram obtidas pela gelatina bovina, que se distinguiu das demais, que não diferiram entre si. Fazendo-se uma projeção do ganho de massa seca por hectare (MSPA ha ${ }^{-1}$ ) verifica-se que a aplicação de gelatina bovina aumentou a massa seca em $22,32 \%$ em relação à aplicação via sementes (Tabela 4).

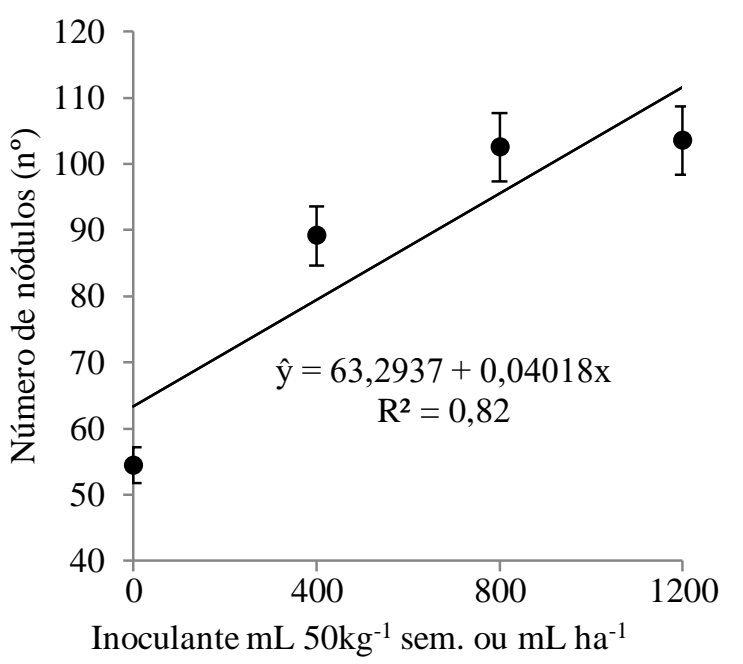

Figura 7. Número de nódulos de plantas de soja sob a aplicação de doses de inoculante Bradyrhizobium japonicum aplicado via sementes, foliar gelatina bovina e gelatina a base de ágar. 
Tabela 4 - Número de nódulos, Massa seca de parte aérea e massa de nódulos MSNo de soja LG 60174 IPRO em função da via de aplicação de inoculante Bradhryzobium

\begin{tabular}{|c|c|c|c|c|}
\hline $\begin{array}{ll}\text { Vias } & \text { de } \\
\text { inoculação } & \end{array}$ & $\mathrm{N}^{0}$ nódulos & MSPA & MSNo & MSPA ha \\
\hline Sementes & $116,69 \mathrm{a}$ & $24,46 \mathrm{~b}$ & $4,22 \mathrm{a}$ & $5961,86 \mathrm{~b}$ \\
\hline Foliar & $84,75 \mathrm{~b}$ & $25,89 \mathrm{~b}$ & $3,14 \mathrm{a}$ & $6009,11 \mathrm{~b}$ \\
\hline Ágar & $75,75 \mathrm{~b}$ & $25,03 \mathrm{~b}$ & $1,19 \mathrm{~b}$ & $6222,86 \mathrm{~b}$ \\
\hline Bovino & $72,44 \mathrm{~b}$ & $31,98 \mathrm{a}$ & $1,22 \mathrm{~b}$ & $7675,46 \mathrm{a}$ \\
\hline DMS & 4,78 & 0,81 & 0,79 & 187,33 \\
\hline $\mathrm{CV}(\%)$ & 21,02 & 12,13 & 30,32 & 11,59 \\
\hline
\end{tabular}

As médias seguidas de letras diferentes diferem entre si ao nível de $5 \%$ de probabilidade pelo teste de Tukey.

Deve-se ressaltar que nos tratamentos em geral a nodulação atingiu ótimos níveis com valores bastante expressivos atingindo 116,69 nódulos na inoculação ocorrida via sementes. Uma das hipóteses de tal sucesso na inoculação pode ter sido a não aplicação de tratamento fitossanitário nas sementes. A aplicação de inoculantes via semente, nem sempre é eficiente, principalmente pela aplicação conjunta de fungicidas, inseticidas e micronutrientes. O tratamento de sementes contribui para causar toxidez às bactérias, e danos às vezes irreversíveis às sementes [11]. Normalmente as misturas carbendazin + thiram $e$ thiabendazole + thiram, independente da peliculização, reduziram o número de nódulos [11].

Percebeu-se um antagonismo entre a formação de nódulos e o desenvolvimento vegetativo/formação de clorofila nas folhas. Esperava-se que havendo maior nodulação nas raízes haveria maior crescimento vegetativo, porém não foi o que ocorreu, os tratamentos com a aplicação da mistura com gelatina foram os com maior crescimento vegetativo/formação de clorofila.

Segundo [3], a possível explicação para a não correlação direta entre nodulação e crescimento vegetativo/produtividade está na existência de vários processos complexos envolvidos no uso de nitrogênio, tais como: absorção, assimilação e re-translocação do $\mathrm{N}$ em toda a planta de soja.

Em relação a este resultado devem-se levar em consideração alguns fatores, em primeiro lugar atentar para a viabilidade dos nódulos que se formaram [12], citam a importância da viabilidade dos nódulos para assimilação de $\mathrm{N}$ pelas plantas, muitas vezes os nódulos estão presentes, mas não viáveis, sendo na realidade parasitas e não fornecedores de $\mathrm{N}$.

Outro fator é que mesmo havendo menos nódulos ou massa de nódulos, todos os tratamentos tiveram uma nodulação suficiente para o desenvolvimento Segundo [1] a nodulação pode ser considerada efetiva, quando garante o fornecimento de $\mathrm{N}$ requerido por uma planta de soja para seu desenvolvimento normal, ocorre quando o peso de nódulos varia entre 100 e $200 \mathrm{mg}$ planta-1 e o número de nódulos varia de 10 a 30.
Pelos resultados obtidos, a inoculação por aplicação em cobertura em V2, principalmente com adição de gelatina pode ser uma prática comum na cultura da soja, podendo substituir a tradicional inoculação via semente. Entretanto, existe a necessidade de mais trabalhos e comprovação de resultados em outras cultivares, por haverem diferença de resposta quanto à inoculação [7].

\section{Conclusões}

- Os modos de aplicação via gelatina bovina e ágar foram os que mais aumentaram o crescimento vegetativo das plantas de soja.

- A aplicação de inoculante com gelatina bovina e ágar atingiram os maiores valores de índice clorofiloG®.

- A nodulação das plantas de soja é maior com a aplicação feita via semente.

\section{DOSES AND APPLICATION METHODS OF INOCULANT SOYBEAN CROPS}

ABSTRACT: Inoculation is considered one of the most important actions in the soybean industry. The objective of this study was to verify the effect of different doses of inoculant with Bradyrhizobium japonicum under different application methods. The experimental design was a randomized complete block (RCB) with 4 replicates in a $4 \times 3$ factorial experimental design, a total of 12 treatments. The doses were: $0 ; 400 ; 800$ and $1200 \mathrm{~mL}$ of inoculant, $50 \mathrm{~kg}^{-1}$ of seeds or $\mathrm{mL} \mathrm{ha}{ }^{-1}$ when the inoculant was applied to the cover. The three application methods were: on seed, by leaf spray at the V2 stage and directly to soil with the addition of $50 \mathrm{~g}$ of bovine gelatin in $4.0 \mathrm{~L} \mathrm{water}^{-1}$ at the V2 stage. The LG 60174 IPRO cultivar was sowed. The treatments with bovine gelatin and agar obtained the best results on plant height, stem diameter, number of leaves, leaf area, chlorophyll content, and shoot dry mass, presenting the highest averages in the vegetative growth of the plants. Seed application reached the highest mean of number of nodules and dry mass of nodules, especially due to the proximity of the bacterium to the seed. It is believed that the gelatins may have kept the soil moisture higher.

Keywords:Glycine max. Inoculant. Bradyrhizobium japonicum.

\section{Referências}

[1] BRACCINI, A. L.; MARIUCCI, G. E. G.; SUZUKAWA, A. K.; LIMA, L. H da S.; PICCININ, G. G. Co-inoculação e modos de aplicação bradyrhizobium japonicum e Azospirilium e adubação nitrogenada na nodulação das plantas e rendimento da cultura da soja. Sci. Agrar. Parana, v.15, n.1, jan./mar., p. 27-35, 2016. http://dx.doi.org/10.18188/1983-1471/sap.v15n1p27-35. 
[2] BRANDELERO, E. M.; PEIXOTO, C. P.; RALISCH, R. Nodulação de cultivares de soja e seus efeitos no rendimento de grãos. Semina: Ciências Agrárias, Londrina, v. 30, n. 3, p. 581-588, 2009.

[3] CARVALHO, R. P.; VON PINHO, R. G.; DAVIDE, L. M. C. Desempenho de cultivares de milho quanto à eficiência de utilização de nitrogênio. Revista Brasileira de Milho e Sorgo, v.10, p.108- 120, 2011.

[4] FERREIRA, D.F. Sisvar: A computer statistic alanalysis system. Ciência e Agrotecnologia, Lavras, v.35, n.6, p.1039-1042, nov./dez. 2011.

[5] HUNGRIA, M.; CAMPO, R. J.; MENDES, I. C. Fixação biológica do nitrogênio na cultura da soja. Londrina, Embrapa Soja: Circular Técnica 35, 2001. $48 \mathrm{p}$.

[6] HUNGRIA, M.; FRANCHINI, J. C.; CAMPO, R. J.; GRAHAM, P. H. The importance of nitrogen fixation to soybean cropping in South America. In: WERNER, D.; NEWTON, W., eds. Nitrogen fixation in agriculture, forestry, ecology and the environment. Dordrecht, Springer, 2005.

[7] LIBÓRIO, P. H. da S.; TORNELI, I. M. B.; NÓBILE, F. O. de; GUERREIRA R. D.; MIGUEL, F. B.; SILVA, J. A. A. da. Comportamento de cultivares de soja quanto a nodulação e fixação biológica de nitrogênio. Ciência \& Tecnologia: FatecJB, Jaboticabal, v. 7, 2015. Número especial.

[8] MATA, F. de S. D. da; ALMEIDA, J. A. R.; REIS, T. C.; SOUZA, D. S.; ITHANA, M. dos S. Revista Trópica - Ciências Agrárias e Biológicas. v. 5, N. 2, P. 15-22, 2011.

[9] NOGUEIRA, P.D.M.; SENA JÚNIOR, D.G.; RAGAGNIN, V.A. Clorofila foliar e nodulação em soja adubada com nitrogênio em cobertura. Global Science and Technology, v. 3, n. 2, p. 117-124, 2010.

[10] PELEGRIN, A. J. de; NARDINO, M.; FERRARI, M.; CARVALHO, I. R.; SZARESKI, V. J.; BELlE, R.; OTOMAR, B. SOUZA, V. Q. Polímeros hidroretentores na cultura da soja em condições de solo argiloso na região norte do Rio Grande do Sul. Rev. de Ciências Agrárias, Lisboa, v.40, n.1, p.175182, mar. 2017. http://dx.doi.org/10.19084/RCA15162.

[11] PEREIRA, C. E.; OLIVEIRA, J. A.; CALDEIRA, C. M.; BOTELHO, F. J. E. Efeito do tratamento das sementes de soja com fungicidas e período de armazenamento na resposta da planta inoculada com Bradyrhizobium. Revista Agro@mbiente On-line, v. 4, n. 2, p. 62-66, jul-dez, 2010.

[12] PEREIRA, C. S.; BUOSI, I.; ZONTA, L. H.; LANGE, A.; FIORINI, I. V. A. Doses de inoculante Bradyrhizobium japonicum em três cultivares de soja no norte de Mato Grosso. Gl. Sci Technol, Rio Verde, v.09, n.01, p.76 - 88, jan/abr. 2016

[13] PEREIRA, C. S.; FARIAS, F. L.; GODOI, C. A. Aplicação de extrato etenólico de própolis (EEP) na nutrição e desenvolvimento de mudas de cafeeiro.Coffee Science, Lavras, v. 9, n. 1, p. 14-23, jan./mar, 2014.

[14] SILVA, P. C. C; COUTO, J.L; SANTOS, A.R. Efeito dos Íons Amônio e Nitrato no Desenvolvimentodo Girassol em Solução Nutritiva. Revista da FZVA. Uruguaiana, v.17, n.1, p. 104-114. 2010

[15] SOUZA, C. C.; OLIVEIRA, F. A.; SIlVA, I. F.; AMORIM NETO, M. S Avaliação de métodos de determinação de água disponível e manejo da irrigação em terra roxa sob cultivo de algodoeiro herbáceo. Revista Brasileira de Engenharia Agrícola e Ambiental, v.4, p.338-342, 2000.

[17] TAIZ, L.; ZEIGER, E. Fisiologia vegetal. 4. ed. Porto Alegre: Artmed, 2009.
[18] UNITED STATES DEPARTMENT OF AGRICULTURE - USDA. Grain: World Markets and Trade. Junho, 2017. Disponível em: https://www.fas.usda.gov/data/grain-world-marketsand-trade. Acesso em: 30 janeiro 2018. 